\title{
Gain-of-Function Mutations in the Transient Receptor Potential Channels TRPV1 and TRPA1: How Painful?
}

\author{
S. BOUKALOVA ${ }^{1}$, F. TOUSKA $^{1}$, L. MARSAKOVA ${ }^{1}$, A. HYNKOVA $^{1}$, L. SURA $^{1}$, \\ S. CHVOJKA ${ }^{1}$, I. DITTERT ${ }^{1}$, V. VLACHOVA ${ }^{1}$
}

${ }^{1}$ Department of Cellular Neurophysiology, Institute of Physiology Academy of Sciences of the Czech Republic, Prague, Czech Republic

Received August 30, 2013

Accepted September 12, 2013

\section{Summary}

Gain-of-function (GOF) mutations in ion channels are rare events, which lead to increased agonist sensitivity or altered gating properties, and may render the channel constitutively active. Uncovering and following characterization of such mutants contribute substantially to the understanding of the molecular basis of ion channel functioning. Here we give an overview of some GOF mutants in polymodal ion channels specifically involved in transduction of painful stimuli - TRPV1 and TRPA1, which are scrutinized by scientists due to their important role in development of some pathological pain states. Remarkably, a substitution of single amino acid in the S4-S5 region of TRPA1 (N855S) has been recently associated with familial episodic pain syndrome. This mutation increases chemical sensitivity of TRPA1, but leaves the voltage sensitivity unchanged. On the other hand, mutations in the analogous region of TRPV1 (R557K and G563S) severely affect all aspects of channel activation and lead to spontaneous activity. Comparison of the effects induced by mutations in homologous positions in different TRP receptors (or more generally in other distantly related ion channels) may elucidate the gating mechanisms conserved during evolution.

\section{Key words}

TRPV1 • TRPA1 • Gain-of-function mutation • Spontaneous activity $\bullet$ Gating $\bullet$ Nociception

\section{Corresponding author}

V. Vlachova, Institute of Physiology AS CR, Videnska 1083, 14220 Prague 4, Czech Republic. Fax: 420-29644-2488. E-mail: vlachova@biomed.cas.cz

\section{Introduction}

The family of Transient Receptor Potential (TRP) ion channels mediates numerous sensory transduction processes, such as thermosensation, mechanosensation, sensation of irritative chemicals and different kinds of taste (for more information, see the TRP channel database: http://www.iuphardb.org/DATABASE/FamilyMenuForward?familyId=78). As the voltage dependent potassium $\left(K_{v}\right)$ channels, the TRP channels consist of four subunits, each with $\mathrm{N}$ - and C-terminal cytoplasmic domains, six transmembrane regions (S1-S6) and the central pore lined by S5 and S6 together with the loop between them (Fig. 1A) (Moiseenkova-Bell and Wensel 2011, Kalia and Swartz 2013). Among TRP channels, TRPV1 and TRPA1 are known to be specialized to transduce painful stimuli in mammals (Moran et al. 2011, Nilius and Owsianik 2011, Nilius et al. 2012). High temperature, low $\mathrm{pH}$ and some natural pungent compounds such as capsaicin act on TRPV1 to elicit nociception. TRPA1 is targeted by many environmental irritants including allyl isothiocyanate, responsible for the pungent taste of horseradish, and cinnamaldehyde from cinnamon. The activity of both channels is also modulated by voltage, but their sensitivity to depolarization is much lower than in $\mathrm{K}_{\mathrm{v}}$ channels. Different parts of TRP channels are responsible for the sensitivity to different agonists (Nilius and Owsianik 2011, Winter et al. 2013). Due to the resulting allosteric gating, it is necessary to have in mind the complex character of TRP channels when evaluating the 
mutational analysis data. Gain-of-function (GOF) mutation may enhance the responses of the channel to one type of stimuli, but sensitivity to other agonists may be unchanged or even diminished. Amino acid substitutions which affect gating can lead to altered phenotype regarding to all aspects of channel activation (Myers et al. 2008b, Minor 2009, Pertusa et al. 2012). Such GOF mutations are invaluable in elucidating the mechanisms of signal transduction from different domains of the protein complex to channel gating.
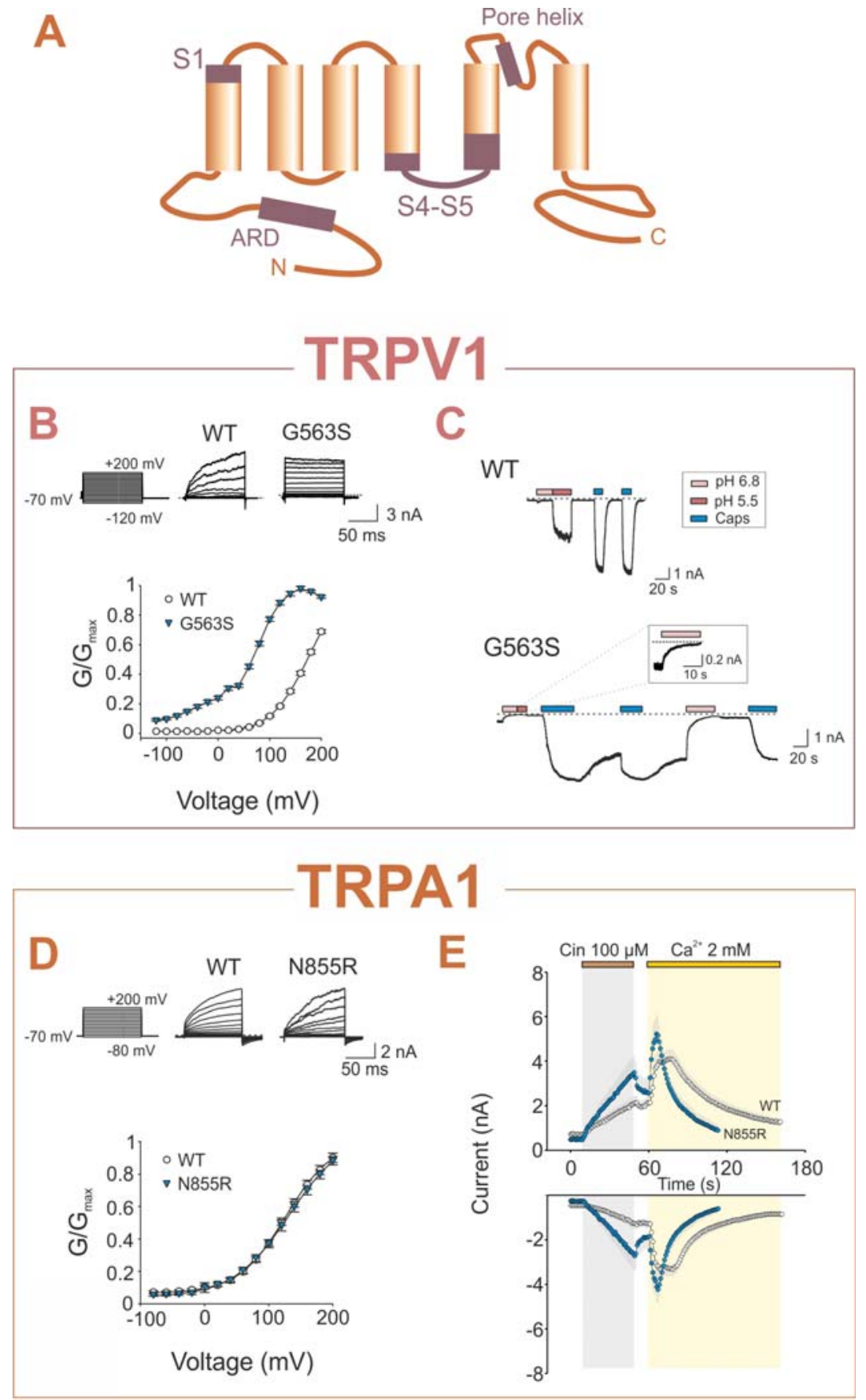

Fig. 1. (A) The topology of TRP channel subunit, that is formed by six transmembrane spanning domains (in orange), $\mathrm{N}$ - and $\mathrm{C}$ cytoplasmatic ends. N-terminus contains ankyrin repeat domain (ARD), that is important in channel regulation. The regions containing gain-of-function mutation of TRP channels are depicted in darker color extracellular part of the first transmembrane domain S1, loop between S4 and S5 helix (S4-S5) and the pore helix situated in the linker between S5 and S6. (B) Upper traces, representative whole cell patch clamp current recordings in response to voltage steps (from $-120 \mathrm{mV}$ to $+200 \mathrm{mV}$ ) in HEK293T cells transfected with wild-type TRPV1 and G563S mutant. Lower trace, normalized conductance-voltage relationship obtained from steady state currents at the end of the pulse. The voltage depencence of G563S mutant is shifted towards less depolarizing voltages compared to wild-type TRPV1. (C) The sample recording of whole cell current responses of wild-type TRPV1 (upper trace) and G563S mutant (lower trace) to consecutive applications of low $\mathrm{pH}$ and $1 \mu \mathrm{M}$ capsaicin. Holding potential $-70 \mathrm{mV}$. Note the inhibitory effect of protons $(\mathrm{pH}$ 6.8) on TRPV1-G563S channel function, shown in inset. (D) Upper traces, representative current traces of wild-type TRPA1 and its N855R mutant in response to indicated voltage step protocol (voltage steps from $-80 \mathrm{mV}$ to $+200 \mathrm{mV}$; increment $+20 \mathrm{mV}$; holding potential $-70 \mathrm{mV}$ ). Lower trace, normalized conductance-voltage relationship for wild-type TRPA1 (white symbols) and N855R mutant (blue symbols) fitted with Boltzmann equation. The data were obtained using the same voltage step protocol as shown in upper traces. (E) Time course of representative whole cell currents through human TRPA1 measured at $+80 \mathrm{mV}$ (upper trace) and $-80 \mathrm{mV}$ (lower trace). The horizontal bars above the records indicate the duration of $100 \mu \mathrm{M}$ cinnamaldehyde and $\mathrm{Ca}^{2+}$ application. The chemical sensitivity of N855R mutant is increased and the inactivation kinetics is faster than in wild-type TRPA1. The voltage dependence of N855R mutant is unchanged. The data represent the means \pm standard error.

\section{GOF mutants in TRPV1 - proton sensitized or inhibited?}

Several GOF mutants of the TRPV1 ion channel were revealed by unbiased genetic screening of a randomly generated population of TRPV1 mutants, which were tested for the ability to cause growth defects when expressed in yeast strains (Myers et al. 2008a). Two of the uncovered mutations, K160E and K155E, are located in the ankyrin repeat domain (ARD). These two 
lysine residues were previously shown to modulate TRPV1 sensitivity and desensitization properties by binding ATP and calmodulin (Lishko et al. 2007). The study of Myers and colleagues (2008a) also revealed the important role of the outer pore region in TRPV1 gating. When mutated, the phenylalanine F640 and adjacent threonine T641 residues located in the putative flexion between pore helix and selectivity filter render the TRPV1 channel constitutively active with increased basal activity and enhanced chemical sensitivity. The authors hypothesised that F640L and T641S mutations mimic the proton-potentiated state, as they were insensitive to proton-mediated potentiation.

In our project aimed at mutational analysis of the transmembrane region of the TRPV1 ion channel, we depicted several overactive mutants with strikingly similar phenotypic properties comprising increased basal activity and voltage sensitivity, altered kinetics of capsaicin-induced responses and incomplete deactivation after capsaicin washout. In contrast to wild-type TRPV1, low $\mathrm{pH}$ neither activates nor potentiates these GOF mutants, but instead stabilize their resting conformation (Pertusa et al. 2012) (Fig. 1B,C). These findings were surprising to us, considering that the mutations are located in distant regions of the protein subunit, such as (i) extracellular portion of $\mathrm{S} 1$ (R455K mutation), (ii) lower part of S4 and S4-S5 linker (R557K and G563S) and (iii) pore helix (T633A) (Boukalova et al. 2013).

Uncovering the GOF mutations in the S4/S4-S5 region is consistent with its putative role in voltage sensing and signal transduction from peripheral domains (S1-S4) to the pore-forming domain subsequently leading to the opening or closing of the channel (Boukalova et al. 2010). On the other hand, finding of constitutively active mutant with single amino acid substitution in the peripheral region of TRPV1 protein complex was not expected. So far, R455K is the only overactive mutation found in the S1-upper S4 region of TRPV1 protein complex, which forms binding capsule for chemical agonists (Jordt and Julius 2002, Gavva et al. 2004), but which direct role in ion channel gating was not presumed. According to previously published homology model of TRPV1 tetramer (Brauchi et al. 2007), it seems that arginine R455 and threonine T633 in the pore helix of adjacent subunit could be in close proximity. We hypothesized that, in analogy to $K_{v}$ channels, S1-pore interface between neighbouring subunits of TRPV1 might serve to stabilize conformations associated with channel gating (Lee et al. 2009). This presumption could explain the similarity of R455K and T633A mutant phenotypes and the crucial role of arginine in S1 in TRPV1 gating.

The most prominent feature of the GOF mutants described recently by us is the lack of low pH-induced activation. Conversely, relatively mild acidification of the extracellular solution inhibits the spontaneous activity and also the inward current remaining after capsaicin washout in R455K, R557K, G563S and T633A (Fig. 1C). Unlike in the outer pore region mutants F640L and T641S (Myers et al. 2008a), the phenotype of these mutants cannot be simply explained as mimicking the proton-potentiated state of TRPV1, as they failed to be activated by severe acidification of the extracellular solution (pH 5.5). In addition, in R455K, T633A and the S4-S5 overactive mutants we observed significantly slowed kinetics of the first capsaicin-induced response, which does not correspond to low $\mathrm{pH}$-stimulated wildtype TRPV1 characterized by much faster onset rate of responses elicited by capsaicin.

In R455K, R557K, G563S and T633A, the washout phase of current responses after removal of capsaicin was markedly slowed down and the current did not deactivate to the basal level. The subsequent application of capsaicin led to rapid augmentation of the current amplitude, which in some cells was followed by again much slower onset phase (Fig. 1C). It appears that once exposed to capsaicin, the closed state of mutant ion channels is acutely destabilized. On the other hand, mild acidification of the extracellular space $(\mathrm{pH}$ 6.8) resulted in rapid and irreversible deactivation of the basal activity and also the current remaining after capsaicin washout. Overall, it seems that the overactive mutants can adopt at least two modes of activation and it is possible to switch between them using either capsaicin (to open the channel and leave it opened) or low $\mathrm{pH}$ (to close the channel and leave it closed). The question is whether this feature is unique for the GOF mutants, or whether it reflects innate phenotypic aspects of wild-type TRPV1 unmasked by the mutations. The later option is favoured by the fact that the same phenotype is found in several TRPV1 mutants with single amino acid substitution in different parts of the protein.

\section{Gain-of-function: which function of the many?}

High throughput unbiased functional screens and a combination of molecular evolution-selection 
approaches helped to reveal a number of interesting mutants in TRPV1, TRPV3 and TRPM8 channels (Bandell et al. 2006, Grandl et al. 2008, 2010, Myers et al. 2008a). Pools of many thousands of mutants have been explored using random mutagenesis and calcium imaging in transfected HEK293 cells which led to the identification of some key regions of these channels that are likely to be important for channel activation or pore permeation (Pertusa et al. 2012). However, for the 250 residue transmembrane part of the TRPV1 channel subunit, for example, the theoretical number of possible sequences is $20^{250}$ which is a number exceeding our imagination and all our experimental capacities. Moreover, for the thermosensitive TRP channels, the prototypically polymodal ion channels, it is important to test as many aspects of function as possible for each mutant because the activation modes can be readily uncoupled. No doubt, the chance of discovering a mutation that changes the function of an ion channel has to be greatly increased by combining an appropriate analogy, reasoning and informed intuition.

In our recent project focused on the sixth transmembrane domain of the human transient receptor potential ankyrin receptor subtype 1 (TRPA1) channel (Story et al. 2003, Jordt et al. 2004), we aimed to identify residues that are likely to be core elements of the gating mechanism (Benedikt et al. 2009). This channel can be activated by a vast number of pungent and irritant chemicals that either covalently interact with (isothiocyanates, cinnamaldehyde, acrolein, allicin, oxidants and lipid peroxidation products) or bind to TRPA1 (cannabinoids, icilin, eugenol, thymol, nicotine), and can also be activated by deep cooling $\left(<17^{\circ} \mathrm{C}\right)$ or depolarizing $(>+100 \mathrm{mV})$ voltages (Bandell et al. 2004, Corey et al. 2004, Bautista et al. 2005, Macpherson et al. 2005, Nagata et al. 2005, Sawada et al. 2007, Caceres et al. 2009, Hu et al. 2009, Karashima et al. 2009, Andrade et al. 2012, Nilius et al. 2012). Using mutagenesis, electrophysiology and sequence homology with certain potassium and sodium channels, we identified several residues within the S6 inner pore-forming region that contribute to allyl isothiocyanate (AITC) and voltagedependent gating. We found that alanine substitution in the conserved mid-S6 proline (P949A) strongly affected the activation/deactivation and ion permeation. The P949A was functionally restored by substitution with a glycine but not by the introduction of a proline at positions $-1,-2$ or +1 , which indicated that, just like in $\mathrm{K}_{\mathrm{v}}$ channels, a flexible residue in the middle of S6 is structurally required for the normal functioning of the TRPA1 channel. Notably, we found a residue N954, at which alanine substitution generated a constitutively open (i.e. GOF) phenotype, suggesting a role in stabilizing the closed conformation. In a prospective unbiased functional screen, this mutant would probably remain unrecognized or misinterpreted as a loss-of-function, because AITC, at first, only slightly potentiates the currents through the N954A channels, but this is followed by a complete inactivation at negative membrane potentials (Benedikt et al. 2009). Our results also pointed to important functional roles for the two distal glycines G958 and G962, comprising the distal GXXXG-motif. The G958A "GOF" mutation strongly decreased the inactivation rate of AITC-induced whole-cell currents, whereas the G962A mutation led to a dramatically delayed onset of the secondary phase of AITC-induced activation, indicating that the distal G962 stabilizes the open conformation. G958, on the other hand, provides additional tuning leading to decreased channel activity. It seems likely that these two glycines play a role similar to that of the distal bi-glycine motif $\mathrm{G}(X)_{3} \mathrm{G}$ of the conserved IS6 domain of the $\mathrm{Ca}_{\mathrm{V}} 1.2$ and $\mathrm{Ca}_{\mathrm{V}} 2.3$ channels (Raybaud et al. 2006).

In fact, for the polymodal TRPA1 ion channel, it is not easy even only to define what is the "gain-offunction" because the channel has various activation modes and undergoes desensitization which depends on many factors, including its own activity (Story et al. 2003, Jordt et al. 2004, Nilius and Owsianik 2011, Nilius et al. 2012). For example, by performing the systemic neutralization of 27 positively charged residues within the C-terminal tail of human TRPA1, we identified eight residues that are important to the allosteric regulation of the channel by chemical and voltage stimuli (K969, R975, K989, K1009, K1046, K1071, K1092, and R1099). In addition, we revealed three charge-neutralizing "GOF" mutants (R975A, K988A, and K989A) which exhibited higher sensitivity to depolarizing voltages, indicating that these residues may be directly involved in the voltagedependent regulation (Samad et al. 2011). However, the currents induced by AITC at negative membrane potentials were small or indistinguishable from wild-type in these mutants.

\section{GOF mutants in the distal C-terminal acidic motif of TRPA1}

An ubiquitous and physiologically important modulator of TRPA1 are calcium ions $\left(\mathrm{Ca}^{2+}\right)$, which enter 
through the open channel, or are released from internal stores, and dynamically control channel opening probability, unitary conductance, ion selectivity (Nagata et al. 2005, Cavanaugh et al. 2008, Patil et al. 2010, Nilius and Owsianik 2011), but also surface expression levels (Schmidt et al. 2009). Intracellular $\mathrm{Ca}^{2+}$ ions activate the channel at micromolar concentrations $\left(\mathrm{EC}_{50}=0.9-6 \mu \mathrm{M}\right)$ (Doerner et al. 2007, Zurborg et al. 2007) and strongly potentiate chemically and voltageinduced responses (Wang et al. 2008). This potentiation is followed by an almost complete and irreversible inactivation, and both processes are accelerated at higher intracellular concentrations of $\mathrm{Ca}^{2+}$. In our recent study, we identified the residues within the distal C-terminal domain of TRPA1 that when mutated affected the $\mathrm{Ca}^{2+}$. and voltage-dependent gating of the channel (Sura et al. 2012). This study revealed several acidic residues in the TRPA1 cytosolic C-terminus that play important roles in $\mathrm{Ca}^{2+}$-dependent modulation and may represent a candidate region for the site of $\mathrm{Ca}^{2+}$ binding. According to our molecular dynamics simulations, the $\mathrm{I}^{1074}$ ISETEDDDS $^{1083}$ motif has been shown to form a $\mathrm{Ca}^{2+}$ binding loop, in which the two residues D1080 and D1082 are predicted to be crucial for binding $\mathrm{Ca}^{2+}$, whereas the side chains of I1074 and E1077 are in contact with the calcium ion using their main chain carbonyl oxygen atoms. We identified residues E1073, E1077, D1080, D1081, and D1082, the specific properties of which are not involved in cinnamaldehyde activation but all appear to be most important for the modulation of the TRPA1 channel by $\mathrm{Ca}^{2+}$. Notably, we found two mutants in this region, E1077A and E1077K, in which the degree of potentiation of cinnamaldehyde responses by $2 \mathrm{mM} \mathrm{Ca}{ }^{2+}$ was markedly reduced obviously due to their initial close-to-saturation state at $+80 \mathrm{mV}$. We reasoned that this sensitizing effect might reflect either a gain-of-function (constitutively active) phenotype or tonic activation due to an increased expression of the mutant channels on the cell surface. In this region, we identified two strong consensus phosphorylation motifs containing S1076 and T1078, both predicted to be targeted by casein kinase CK2. Therefore, we tested additional mutants in which either serine or threonine were replaced by either alanine or aspartate to mimic the nonphosphorylated and phosphorylated forms of the TRPA1 protein, respectively. We found that the nonphosphorylatable mutant S1076A and the phosphorylation-mimicking S1076D mutant channels were normal in all general aspects of functionality. Mutation T1078A exhibited substantially reduced responses to voltage and cinnamaldehyde and was capable of strong potentiation by $2 \mathrm{mM} \mathrm{Ca}^{2+}$, whereas mutation T1078D resulted in TRPA1 channels whose conductance to voltage relationships were also strongly augmented and shifted toward less depolarizing potentials. These findings indicate that the functional changes caused by other substitutions in this region are likely to be steric or local, rather than related to changes in the phosphorylationdependent membrane insertion of the channels. We, however, did not exclude the possible involvement of these amino acid residues in the recently proposed mechanism by which localized $\mathrm{Ca}^{2+}$ influx upon channel activation controls TRPA1 functionality through its acute translocation to the membrane (Schmidt et al. 2009).

\section{GOF mutant of TRPA1 - pain-related channelopathy}

The TRPA1 channel has been recently linked to a heritable human pain disorder (Kremeyer et al. 2010). In the S4-S5 linker of TRPA1, the missense mutation N855S that leads to increased channel activity has been revealed as a cause of familial episodic pain syndrome manifested as paroxysmal pain induced by tiredness, fasting or cold (Kremeyer et al. 2010). In their study, the authors demonstrate that the N855S mutant exhibits a 4-fold increase in inward currents on activation by cinnamaldehyde, menthol, the endogenous aldehyde 4-hydroxynonenal, or cold at normal resting membrane potentials. Removing extracellular $\mathrm{Ca}^{2+}$ ions shifted the voltage-dependent activation by $+20 \mathrm{mV}$ in both the wild-type and the N855S mutant, but under the $\mathrm{Ca}^{2+}$-free conditions, the cooperativity of voltage-dependent gating decreased only in N855S, but not in the wild-type TRPA1 channels. This finding was interpreted as indicating that this mutation might destabilize the closed conformation of the channel, which could account for a more general effect on channel gating (Smith-Maxwell et al. 1998) and is consistent with the proposed functional role for the S4-S5 linker in the gating of other thermosensitive TRP channels (Brauchi et al. 2007, Voets et al. 2007, Boukalova et al. 2010). It is generally accepted that the electrophilic compounds, such as allyl isothiocyanate activate TRPA1 through covalent binding at specific cysteine residues on the intracellularly located N-terminus (Hinman et al. 2006, Macpherson et al. 2007, Kang et al. 2010). It is, however, not known how 
covalent cysteine modifications translate into TRPA1 activation. Simulations based on a low-resolution electron density map indicate that the chemical signal can be readily conveyed through cytoplasmic domains to the intracellular channel gate (Cvetkov et al. 2011). Although to discern the individual activation pathways in TRPA1 is very difficult even if we knew the actual structure of the channel (Cvetkov et al. 2011), it can be supposed that, analogous to $K_{v}$ channels, the conformational changes within the S1-S4 "sensors" are converted by the inner S4-S5 linker helices directly into gate opening and closing through the motions of the S6 inner helices which dilate (open) and constrict (close) the pore entryway (Long et al. 2005a,b, 2007, Brauchi et al. 2007, Benedikt et al. 2009, Salazar et al. 2009). Interestingly, we found that the introduction of a positively charged residue at position N855 (N855R) increased the TRPA1-mediated current responses to cinnamaldehyde and speeded up the inactivation kinetics without affecting conductance to voltage relationships (Fig. 1D,E). This indicates that the mutation altered the chemical but not the voltage activation pathway of the TRPA1 channel.

\section{Future perspectives}

Chronic pain conditions, resulting from disease, injury or inherited, cause unimaginable suffering and constitute a huge burden for the individual and society. Both, TRPV1 and TRPA1 are implicated in acute and chronic pain states and are intensively studied as potential therapeutic targets (Brederson et al. 2013). Mutations in genes encoding ion channels associated with nociceptive pathways, e.g. voltage-gated sodium, potassium and calcium channels, TRP channels, ASIC channels or purinergic receptors, have been described to cause a variety of pathological states (Cregg et al. 2010, Lampert et al. 2010, Raouf et al. 2010, Nilius and Voets 2013, Waxman 2013). It is likely that with ongoing research further mutations will emerge and therefore future structural and functional studies will be necessary to enhance our understanding of the unique features of these channels and to elucidate how their pain-related functioning can be manipulated to therapeutic advantage.

\section{Conflict of Interest}

There is no conflict of interest.

\section{Acknowledgements}

This work was supported by the Grant Agency of the Czech Republic (305/09/0081 and 304/12/G069), GAUK 500512 and 888513, CZ.1.07/2.3./00/30.0025, and the Research Project Fund of the Academy of Sciences of the Czech Republic RVO:67985823.

\section{References}

ANDRADE EL, MEOTTI FC, CALIXTO JB: TRPA1 antagonists as potential analgesic drugs. Pharmacol Ther 133: 189-204, 2012.

BANDELL M, STORY GM, HWANG SW, VISWANATH V, EID SR, PETRUS MJ, EARLEY TJ, PATAPOUTIAN A: Noxious cold ion channel TRPA1 is activated by pungent compounds and bradykinin. Neuron 41: 849-857, 2004.

BANDELL M, DUBIN AE, PETRUS MJ, ORTH A, MATHUR J, HWANG SW, PATAPOUTIAN A: Highthroughput random mutagenesis screen reveals TRPM8 residues specifically required for activation by menthol. Nat Neurosci 9: 493-500, 2006.

BAUTISTA DM, MOVAHED P, HINMAN A, AXELSSON HE, STERNER O, HOGESTATT ED, JULIUS D, JORDT SE, ZYGMUNT PM: Pungent products from garlic activate the sensory ion channel TRPA1. Proc Natl Acad Sci USA 102: 12248-12252, 2005.

BENEDIKT J, SAMAD A, ETTRICH R, TEISINGER J, VLACHOVA V: Essential role for the putative S6 inner pore region in the activation gating of the human TRPA1 channel. Biochim Biophys Acta Mol Cell Research 1793: 1279-1288, 2009.

BOUKALOVA S, MARSAKOVA L, TEISINGER J, VLACHOVA V: Conserved residues within the putative S4-S5 region serve distinct functions among thermosensitive vanilloid transient receptor potential (TRPV) channels. J Biol Chem 285: 41455-41462, 2010.

BOUKALOVA S, TEISINGER J, VLACHOVA V: Protons stabilize the closed conformation of gain-of-function mutants of the TRPV1 channel. Biochim Biophys Acta 1833: 520-528, 2013. 
BRAUCHI S, ORTA G, MASCAYANO C, SALAZAR M, RADDATZ N, URBINA H, ROSENMANN E, GONZALEZ-NILO F, LATORRE R: Dissection of the components for PIP2 activation and thermosensation in TRP channels. Proc Natl Acad Sci USA 104: 10246-10251, 2007.

BREDERSON JD, KYM PR, SZALLASI A: Targeting TRP channels for pain relief. Eur J Pharmacol 716: 61-76, 2013.

CACERES AI, BRACKMANN M, ELIA MD, BESSAC BF, DEL CAMINO D, D'AMOURS M, WITEK JS, FANGER CM, CHONG JA, HAYWARD NJ, HOMER RJ, COHN L, HUANG X, MORAN MM, JORDT SE: A sensory neuronal ion channel essential for airway inflammation and hyperreactivity in asthma. Proc Natl Acad Sci USA 106: 9099-9104, 2009.

CAVANAUGH EJ, SIMKIN D, KIM D: Activation of transient receptor potential A1 channels by mustard oil, tetrahydrocannabinol and $\mathrm{Ca}(2+)$ reveals different functional channel states. Neuroscience 154: 1467-1476, 2008.

COREY DP, GARCIA-ANOVEROS J, HOLT JR, KWAN KY, LIN SY, VOLLRATH MA, AMALFITANO A, CHEUNG EL, DERFLER BH, DUGGAN A, GELEOC GS, GRAY PA, HOFFMAN MP, REHM HL, TAMASAUSKAS D, ZHANG DS: TRPA1 is a candidate for the mechanosensitive transduction channel of vertebrate hair cells. Nature 432: 723-730, 2004.

CREGG R, MOMIN A, RUGIERO F, WOOD JN, ZHAO J: Pain channelopathies. J Physiol (Lond) 588: 1897-1904, 2010.

CVETKOV TL, HUYNH KW, COHEN MR, MOISEENKOVA-BELL VY: Molecular architecture and subunit organization of TRPA1 ion channel revealed by electron microscopy. J Biol Chem 286: 38168-38176, 2011.

DOERNER JF, GISSELMANN G, HATT H, WETZEL CH: Transient receptor potential channel A1 is directly gated by calcium ions. J Biol Chem 282: 13180-13189, 2007.

GAVVA NR, KLIONSKY L, QU Y, SHI L, TAMIR R, EDENSON S, ZHANG TJ, VISWANADHAN VN, TOTH A, PEARCE LV, VANDERAH TW, PORRECA F, BLUMBERG PM, LILE J, SUN Y, WILD K, LOUIS JC, TREANOR JJ: Molecular determinants of vanilloid sensitivity in TRPV1. J Biol Chem 279: 20283-20295, 2004.

GRANDL J, HU H, BANDELL M, BURSULAYA B, SCHMIDT M, PETRUS M, PATAPOUTIAN A: Pore region of TRPV3 ion channel is specifically required for heat activation. Nat Neurosci 11: 1007-1013, 2008.

GRANDL J, KIM SE, UZZELL V, BURSULAYA B, PETRUS M, BANDELL M, PATAPOUTIAN A: Temperatureinduced opening of TRPV1 ion channel is stabilized by the pore domain. Nat Neurosci 13: 708-714, 2010.

HINMAN A, CHUANG HH, BAUTISTA DM, JULIUS D: TRP channel activation by reversible covalent modification. Proc Natl Acad Sci USA 103: 19564-19568, 2006.

HU H, BANDELL M, PETRUS MJ, ZHU MX, PATAPOUTIAN A: Zinc activates damage-sensing TRPA1 ion channels. Nat Chem Biol 5: 183-190, 2009.

JORDT SE, JULIUS D: Molecular basis for species-specific sensitivity to "hot" chili peppers. Cell 108: 421-430, 2002.

JORDT SE, BAUTISTA DM, CHUANG HH, MCKEMY DD, ZYGMUNT PM, HOGESTATT ED, MENG ID, JULIUS D: Mustard oils and cannabinoids excite sensory nerve fibres through the TRP channel ANKTM1. Nature 427: 260-265, 2004.

KALIA J, SWARTZ KJ: Exploring structure-function relationships between TRP and Kv channels. Sci Rep 3: 1523, 2013.

KANG K, PULVER SR, PANZANO VC, CHANG EC, GRIFFITH LC, THEOBALD DL, GARRITY PA: Analysis of Drosophila TRPA1 reveals an ancient origin for human chemical nociception. Nature 464: 597-600, 2010.

KARASHIMA Y, TALAVERA K, EVERAERTS W, JANSSENS A, KWAN KY, VENNEKENS R, NILIUS B, VOETS T: TRPA1 acts as a cold sensor in vitro and in vivo. Proc Natl Acad Sci USA 106: 1273-1278, 2009.

KREMEYER B, LOPERA F, COX JJ, MOMIN A, RUGIERO F, MARSH S, WOODS CG, JONES NG, PATERSON KJ, FRICKER FR, VILLEGAS A, ACOSTA N, PINEDA-TRUJILLO NG, RAMIREZ JD, ZEA J, BURLEY MW, BEDOYA G, BENNETT DL, WOOD JN, RUIZ-LINARES A: A gain-of-function mutation in TRPA1 causes familial episodic pain syndrome. Neuron 66: 671-680, 2010.

LAMPERT A, O'REILLY AO, REEH P, LEFFLER A: Sodium channelopathies and pain. Pflugers Arch 460: 249-263, 2010. 
LEE SY, BANERJEE A, MACKINNON R: Two separate interfaces between the voltage sensor and pore are required for the function of voltage-dependent K(+) channels. PLoS Biol 7: e47, 2009.

LISHKO PV, PROCKO E, JIN X, PHELPS CB, GAUDET R: The ankyrin repeats of TRPV1 bind multiple ligands and modulate channel sensitivity. Neuron 54: 905-918, 2007.

LONG SB, CAMPBELL EB, MACKINNON R: Crystal structure of a mammalian voltage-dependent Shaker family K+ channel. Science 309: 897-903, 2005a.

LONG SB, CAMPBELL EB, MACKINNON R: Voltage sensor of Kv1.2: structural basis of electromechanical coupling. Science 309: 903-908, 2005b.

LONG SB, TAO X, CAMPBELL EB, MACKINNON R: Atomic structure of a voltage-dependent $\mathrm{K}+$ channel in a lipid membrane-like environment. Nature 450: 376-382, 2007.

MACPHERSON LJ, GEIERSTANGER BH, VISWANATH V, BANDELL M, EID SR, HWANG S, PATAPOUTIAN A: The pungency of garlic: activation of TRPA1 and TRPV1 in response to allicin. Curr Biol 15: 929-934, 2005.

MACPHERSON LJ, DUBIN AE, EVANS MJ, MARR F, SCHULTZ PG, CRAVATT BF, PATAPOUTIAN A: Noxious compounds activate TRPA1 ion channels through covalent modification of cysteines. Nature 445: 541-545, 2007.

MINOR DL JR: Searching for interesting channels: pairing selection and molecular evolution methods to study ion channel structure and function. Mol Biosyst 5: 802-810, 2009.

MOISEENKOVA-BELL V, WENSEL TG: Functional and structural studies of TRP channels heterologously expressed in budding yeast. Adv Exp Med Biol 704: 25-40, 2011.

MORAN MM, MCALEXANDER MA, BIRO T, SZALLASI A: Transient receptor potential channels as therapeutic targets. Nat Rev Drug Discov 10: 601-620, 2011.

MYERS BR, BOHLEN CJ, JULIUS D: A yeast genetic screen reveals a critical role for the pore helix domain in TRP channel gating. Neuron 58: 362-373, 2008a.

MYERS BR, SAIMI Y, JULIUS D, KUNG C: Multiple unbiased prospective screens identify TRP channels and their conserved gating elements. J Gen Physiol 132: 481-486, 2008b.

NAGATA K, DUGGAN A, KUMAR G, GARCIA-ANOVEROS J: Nociceptor and hair cell transducer properties of TRPA1, a channel for pain and hearing. J Neurosci 25: 4052-4061, 2005.

NILIUS B, OWSIANIK G: The transient receptor potential family of ion channels. Genome Biol 12: 218, 2011.

NILIUS B, APPENDINO G, OWSIANIK G: The transient receptor potential channel TRPA1: from gene to pathophysiology. Pflugers Arch 464: 425-458, 2012.

NILIUS B, VOETS T: The puzzle of TRPV4 channelopathies. EMBO Rep 14: 152-163, 2013.

PATIL MJ, JESKE NA, AKOPIAN AN: Transient receptor potential V1 regulates activation and modulation of transient receptor potential A1 by Ca2+. Neuroscience 171: 1109-1119, 2010.

PERTUSA M, MOLDENHAUER H, BRAUCHI S, LATORRE R, MADRID R, ORIO P: Mutagenesis and temperature-sensitive little machines. In: Mutagenesis. MISHRA R (ed), InTech Open Access publisher, Valparaíso, 2012, pp 221-246.

RAOUF R, QUICK K, WOOD JN: Pain as a channelopathy. J Clin Invest 120: 3745-3752, 2010.

RAYBAUD A, DODIER Y, BISSONNETTE P, SIMOES M, BICHET DG, SAUVE R, PARENT L: The role of the GX9GX3G motif in the gating of high voltage-activated Ca2+ channels. J Biol Chem 281: 39424-39436, 2006.

SALAZAR H, JARA-OSEGUERA A, HERNANDEZ-GARCIA E, LLORENTE I, ARIAS O, II, SORIANO-GARCIA M, ISLAS LD, ROSENBAUM T: Structural determinants of gating in the TRPV1 channel. Nat Struct Mol Biol 16: 704-710, 2009.

SAMAD A, SURA L, BENEDIKT J, ETTRICH R, MINOFAR B, TEISINGER J, VLACHOVA V: The C-terminal basic residues contribute to the chemical- and voltage-dependent activation of TRPA1. Biochem $J$ 433: 197-204, 2011.

SAWADA Y, HOSOKAWA H, HORI A, MATSUMURA K, KOBAYASHI S: Cold sensitivity of recombinant TRPA1 channels. Brain Res 1160: 39-46, 2007.

SCHMIDT M, DUBIN AE, PETRUS MJ, EARLEY TJ, PATAPOUTIAN A: Nociceptive signals induce trafficking of TRPA1 to the plasma membrane. Neuron 64: 498-509, 2009. 
SMITH-MAXWELL CJ, LEDWELL JL, ALDRICH RW: Uncharged S4 residues and cooperativity in voltagedependent potassium channel activation. J Gen Physiol 111: 421-439, 1998.

STORY GM, PEIER AM, REEVE AJ, EID SR, MOSBACHER J, HRICIK TR, EARLEY TJ, HERGARDEN AC, ANDERSSON DA, HWANG SW, MCINTYRE P, JEGLA T, BEVAN S, PATAPOUTIAN A: ANKTM1, a TRP-like channel expressed in nociceptive neurons, is activated by cold temperatures. Cell 112: 819-829, 2003.

SURA L, ZIMA V, MARSAKOVA L, HYNKOVA A, BARVIK I, VLACHOVA V: C-terminal acidic cluster is involved in Ca2+-induced regulation of human transient receptor potential ankyrin 1 channel. $J$ Biol Chem 287: 18067-18077, 2012.

VOETS T, OWSIANIK G, JANSSENS A, TALAVERA K, NILIUS B: TRPM8 voltage sensor mutants reveal a mechanism for integrating thermal and chemical stimuli. Nat Chem Biol 3: 174-182, 2007.

WANG YY, CHANG RB, WATERS HN, MCKEMY DD, LIMAN ER: The nociceptor ion channel TRPA1 is potentiated and inactivated by permeating calcium ions. J Biol Chem 283: 32691-32703, 2008.

WAXMAN SG: Painful Na-channelopathies: an expanding universe. Trends Mol Med 19: 406-409, 2013.

WINTER Z, BUHALA A, OTVOS F, JOSVAY K, VIZLER C, DOMBI G, SZAKONYI G, OLAH Z: Functionally important amino acid residues in the transient receptor potential vanilloid 1 (TRPV1) ion channel - an overview of the current mutational data. Mol Pain 9: 30, 2013.

ZURBORG S, YURGIONAS B, JIRA JA, CASPANI O, HEPPENSTALL PA: Direct activation of the ion channel TRPA1 by Ca2+. Nat Neurosci 10: 277-279, 2007. 